\title{
UN OBJETO IMPOSIBLE: ACERCA DEL ANÁLISIS DEL FENÓMENO NACIONAL
}

\author{
Edwin Cruz Rodríguez ${ }^{1}$ \\ Universidad Nacional de Colombia
}

http://dx.doi.org/10.5209/rev_NOMA.2012.v35.n3.42199

\begin{abstract}
Resumen.- Este trabajo plantea una perspectiva de análisis de la nación como resultado de una lucha hegemónica entre sujetos concretos que abanderan proyectos de nación diversos y antagónicos. En primer lugar analiza las principales formas como se ha argumentado la categoría de nación señalando los límites que presentan para la comprensión del fenómeno y, en segundo lugar, reconstruye la perspectiva de análisis de la nación como lucha hegemónica. Más que una esencia trascendente o un conjunto de rasgos tangibles, la nación es una construcción histórica y artificial resultado de relaciones de poder específicas. En consecuencia, el análisis debe centrase en la lucha entre proyectos de nación, encarnados por sujetos concretos, en pugna por dotarla de significado y constituirse en hegemónicos.
\end{abstract}

Palabras clave.- nación, lucha hegemónica, historicidad, sujetos, proyectos de nación

\section{An impossible object: on the analysis of the national phenomenon}

\begin{abstract}
This paper presents a perspective of analysis of the nation as result of a hegemonic struggle between concrete subjects with diverse and antagonistic projects of nation. First analyzes the main forms like has argued the category of nation indicating the limits that they present for the comprehension of the phenomenon and, secondly, it reconstructs the perspective of analysis of the nation as hegemonic struggle. More than a transcendent essence or a set of tangible features, the nation is a historical construction and artificial result of specific power relations. Consequently, the analysis should focus on the struggle between national projects, played by specific subjects, competing by giving it meaning and become hegemonic.
\end{abstract}

Keywords.- nation, hegemonic struggle, historicity, projects of nation

\section{Introducción}

"Nación" es una de las categorías del lenguaje político que evoca menos consenso en las ciencias sociales. Ya se trate de un "caos terminológico" (Connor, 1998: 55111), o de un "fracaso terminológico" (Jaffrelot, 1993: 203), lo cierto es que ninguna teoría de la nación ha podido suscitar una aceptación amplia entre los estudiosos $^{2}$. No obstante, la ausencia de consenso en torno a la definición contrasta con la eficacia política del concepto y su persistencia en el tiempo

\footnotetext{
${ }^{1}$ Candidato a Doctor en estudios políticos y relaciones internacionales de la Universidad Nacional de Colombia.

${ }^{2}$ Para revisiones actualizadas de la literatura sobre nación ver Bolívar (2001) y Santamaría (2005).
} 
(Renaut, 1993: 38). Ello hace pertinente preguntarse ¿cómo proceder al análisis del fenómeno nacional?

Este trabajo aborda esta cuestión reconstruyendo, en primer lugar, las formas como se ha definido la categoría de nación, en distintos enfoques, y en segundo lugar, planteando una perspectiva de análisis que concibe la nación como resultado de una lucha hegemónica. Más que una esencia trascendente o un conjunto de rasgos tangibles, la nación es una construcción histórica y artificial resultado de relaciones de poder específicas. En consecuencia, el análisis debe centrase en la lucha entre proyectos de nación diversos y antagónicos, encarnados por sujetos concretos, en pugna por dotarla de significado y constituirse en hegemónicos.

\section{Los argumentos de la nación}

Pueden distinguirse al menos cuatro formas de argumentación en la definición de la categoría de nación (Cuadro 1). Por un lado, se encuentran las argumentaciones "ontologistas", que la conciben como una esencia o "ser" trascendente a las dinámicas históricas de los sujetos. Esta forma de argumentar puede a su vez subdividirse en dos. Primero, un enfoque espiritualista que ubica la nación como esencia trascendente y eterna. Segundo, una perspectiva "objetivista", que concibe la nación como un conjunto de rasgos que se han formado históricamente y le dan un carácter tangible u objetivo. Desde este punto de vista, constatar la existencia de una nación implica verificar si "cumple" con estos rasgos.

Por otro lado, están las argumentaciones "relativistas" que enfatizan una concepción de la nación como construcción histórica y artificial asignándole en el proceso un papel principal a los sujetos concretos. Este tipo de argumentaciones pueden a su vez subdividirse en, primero, las "objetivistas" que plantean que la "objetividad" de la nación -su carácter tangible- sólo puede verificarse en relación con el Estado moderno, como una cultura compartida que se produce "desde arriba". Esta existencia objetiva de la nación sólo puede constatarse a posteriori, por referencia al Estado, aunque la nación no se identifique con este; lo único que puede constatarse como realidad presente es el nacionalismo, concebido como la aspiración de un movimiento político a conseguir su autodeterminación por medio de la construcción de un Estado propio. En segundo lugar, pueden ubicarse las definiciones "subjetivistas" que también toman la nación como una construcción artificial, pero enfatizan en los factores subjetivos más que en rasgos objetivos. Aquí la existencia de la nación no depende de ninguna característica tangible, y no necesariamente de su referencia al Estado, sino de la imagen o conciencia del grupo sobre sí mismo. 


\section{Cuadro 1. Formas de argumentar la categoría de nación}

\begin{tabular}{|l|l|l|}
\cline { 2 - 3 } \multicolumn{1}{c|}{} & Objetivista & Subjetivista \\
\hline Ontologista & $\begin{array}{l}\text { Conjunto de rasgos que se } \\
\text { han formado históricamente } \\
\text { y le dan un carácter tangible } \\
\text { u objetivo. }\end{array}$ & Esencia o "ser" trascendente \\
a las dinámicas históricas. \\
\hline Relativista & $\begin{array}{l}\text { Cultura compartida que se } \\
\text { produce desde el Estado o } \\
\text { por un movimiento } \\
\text { nacionalista. }\end{array}$ & grupo sobre sí mismo \\
\hline
\end{tabular}

\subsection{El argumento ontologista-subjetivista}

Este tipo de argumentación es el propio de todo discurso nacionalista que pretenda fundar una nación con orígenes divinos o metafísicos. Este enfoque aparece primero en la filosofía de la historia idealista de Fichte, quien en sus Discursos a la nación alemana (1807-08) defiende una perspectiva espiritualista de la nación. Empero, Fichte no está interesado en erigir una norma general para explicar lo nacional, sino sólo conservar la nación alemana ${ }^{3}$. La nación se concibe como una trascendencia, un ente fuera de la historia, "pueblo y patria en esta significación como portador y prenda de la eternidad telúrica y como aquello que puede ser eterno en este mundo" (Fichte, 1968: 148).

Así concebida, la nación adquiere sus contornos definitorios con la conservación de la lengua viva, elemento que trasciende la vida de los sujetos concretos ${ }^{4}$. Además, la conservación de la lengua impone una jerarquización entre pueblos, pues en los pueblos con lengua viva la formación espiritual interviene en la vida, hay un cultivo del espíritu cuya mayor expresión es la poesía, mientras que los pueblos que no conservan su lengua "se abandonan en manos de su feliz naturaleza" (Fichte, 1968: 104). La nación es concebida como aquello eterno en el

\footnotetext{
3 "El medio de formación de una nueva raza, propuesto en estos discursos, tiene que aplicarse antes que nada por alemanes para alemanes y ya se dijo que corresponde en primer término a nuestra nación" (Fichte, 1968: 78)

${ }^{4}$ La lengua es trascendente y tiene una dinámica propia al margen de los sujetos. Distinguiendo los pueblos alemanes que conservan y no conservan el idioma afirma: "no importa la condición particular de la lengua que se conserva de esta estirpe, ni la del otro pueblo del que se toma, sino únicamente tiene significación el hecho de que en el primero se conserva lo propio, mientras que en el segundo caso se toma lo extraño; tampoco cuenta la procedencia de aquellos que continúan hablando una lengua originaria, sino solamente tiene importancia que esta lengua se continúe hablando sin interrupción, ya que los hombres son formados más por la lengua que la lengua por los hombres" (Fichte, 1968: 81).
} 
mundo temporal, capaz de trascender la historicidad propia de la vida individual ${ }^{5}$. De esa forma, se erige como un ser con vida propia más allá de las determinaciones históricas y de los sujetos concretos.

Tal forma de argumentación se mantiene en la obra de Otto Bauer La cuestión de las nacionalidades y la socialdemocracia (1907) y en sus concepciones de "comunidad de destino" y "carácter nacional" como elementos definitorios de la nación. Bauer se esfuerza por introducir la nación en el devenir histórico y criticar la concepción espiritualista acendrada en la tradición alemana: "El espíritu del pueblo no puede explicar la comunidad de carácter nacional, porque él mismo es nada más que el carácter nacional transformado en una esencialidad metafísica, en un espectro" (Bauer, 1979: 30).

De esa forma, pretende aprender el fenómeno de la nación mediante su interpretación de la concepción marxista de la historia. Así, a diferencia de la concepción espiritualista, concibe la comunidad lingüística como apenas una expresión de la comunidad de carácter nacional, no suficiente para definirlo pues este es un proceso amplio e irreductible, "un precipitado de procesos históricos pasados que se vuelve a modificar por obra de procesos históricos subsiguientes" (Bauer, 1979: 10). El carácter nacional es el "complejo de connotaciones físicas y espirituales que distinguen a una nación de otra" (Bauer, 1979: 24) ${ }^{6}$. Pero no está dado por una esencia trascendente sino por el desarrollo histórico de las comunidades nacionales; por ello, en contraste con la concepción espiritualista, "el carácter nacional es modificable. La comunidad de carácter vincula a los miembros de una nación durante determinada época, pero de ningún modo a la nación de nuestro tiempo con sus antepasados de hace dos o tres siglos" (Bauer, 1979: 25).

Todo ello le permite llegar a una definición según la cual "nación es el conjunto de seres humanos vinculados por comunidad de destino en una comunidad de carácter" (Bauer, 1979: 142) ${ }^{7}$. Aunque tal concepción introduce la dimensión

\footnotetext{
5 "Esto es un pueblo en el sentido superior de la palabra tomada desde el punto de vista de de la visión de un mundo espiritual: la totalidad de personas que conviven en una sociedad y que se reproducen por sí mismas natural y espiritualmente de forma continua, el cual en su totalidad está bajo una ley determinada especial de desarrollo de lo divino desde él. Lo común de esta ley especial es lo que en el mundo eterno, y por eso también en el temporal, une esta multitud a un todo natural y preñado de si mismo" (Fichte, 1968: 145).

6 "Esto es lo que tengo en mente cuando hablo del "carácter nacional". Con ello no quiero expresar aquellas imágenes mentirosas de la demagogia nacionalista, que sólo en el propio pueblo descubre héroes y mercaderes en el ajeno. Más bien quiero expresar aquellas diversidades, solamente asequibles a un análisis psicológico mucho más fino y que aparecen en la estructura básica del espíritu, en el gusto intelectual y estético, en el modo de reaccionar a los mismos estímulos, cosas en que fijamos la atención si comparamos la vida espiritual de las diferentes naciones, su ciencia y su filosofía, su poesía, música y arte plástica, su vida pública y social, su estilo y sus hábitos de vida" (Bauer, 1979: 10).

7 "El carácter de los seres humanos nunca está determinado por otra cosa que por su destino; el carácter nacional nunca es otra cosa que el precipitado de la historia de una nación. Las condiciones en que los hombres producen su sustento vital y reparten el fruto de su trabajo determinan el destino de cada pueblo; sobre la base de determinado tipo de producción y reparto
} 
histórica, al igual que la concepción espiritualista continúa aceptando que existe una esencia de la nación que le da su forma distintiva, el "carácter nacional", que se encontraría en un pasado remoto. Con ello nuevamente soslaya la experiencia de los sujetos concretos en la comprensión de la nación.

\subsection{El argumento ontologista-objetivista}

Este tipo de argumentación puede encontrarse en el texto clásico de Stalin (1913), quien enlista una serie de rasgos objetivos para identificar una nación. Stalin (1972: 10) empieza por afirmar que la nación "no es una comunidad racial o tribal, sino una comunidad de hombres, formada históricamente". Aún más, no sólo es una categoría histórica, sino una categoría propia del contexto del "capitalismo ascencional", en el cual la reivindicación nacional es una lucha burguesa, en la medida en que la burguesía pretende construir su propio mercado nacional, y en esa lucha consigue arrastrar al proletariado o segmentos considerables del mismo.

Sin embargo, en la precisión de la categoría nación, las relaciones entre clases ceden en el análisis en favor de la búsqueda de rasgos objetivos que permitan definirla, bajo la creencia que ello permite aprender el problema nacional más allá de las acepciones metafísicas con las que está cargado el concepto de nación. De esa forma, Stalin descarta que la nación pueda ser definida por rasgos aislados como la lengua, el territorio, la vida económica, la psicología o la cultura compartidos. Empero, la conjunción de estos elementos en el devenir histórico si permite definirla pues le confiere un carácter tangible lejos de las inspiraciones espiritualistas que había tenido la categoría. En fin, para Stalin (1972: 14) "nación es una comunidad estable, históricamente formada, de idiomas, de territorio, de vida económica y de psicología, manifestada esta en la comunidad de cultura".

Esta misma lógica en la argumentación se mantiene con algunos cambios formales en la concepción de Anthony Smith (1997), quien intenta aprender el fenómeno nacional mediante la creación de tipos ideales que la distingan de la etnia, el Estado y de fenómenos afines como el nacionalismo, introduciendo al mismo tiempo una lectura histórica o no "primordialista". La etnia tiene como elementos definitorios un gentilicio, un mito de origen común, recuerdos históricos compartidos, elementos de cultura colectiva de carácter diferenciador, asociación con una "patria" específica y un sentido de solidaridad (Smith, 1997: 19). Se distingue de la nación porque, aunque esta también es una comunidad con recuerdos históricos y mitos colectivos, "mientras en el caso de las ethnies el vínculo con el territorio puede ser sólo histórico y simbólico, en el caso de la

del sustento vital surge también determinada cultura espiritual. Pero la historia así determinada de un pueblo tiene doble efecto en sus descendientes: por un lado, mediante el cultivo de determinadas cualidades físicas debido a la lucha por la existencia y a la transferencia de esas cualidades a sus descendientes por la vía de la herencia natural; por otro, mediante la producción de determinados bienes culturales y su transmisión a los descendientes por la educación, las costumbres y el derecho, por la eficacia de la intercomunicación entre los seres humanos" (Bauer, 1979: 43). 
nación es físico y real: las naciones poseen territorios" (Smith, 1997: 36). Además, la nación es un fenómeno propio de la época moderna, por más que por la vía del mito presente unos orígenes étnicos comunes.

Por otra parte, mientras el Estado se reduce a las instituciones públicas, la nación "representa un lazo cultural y político al unir en una única comunidad política a todos los que comparten una cultura y un suelo patrio históricos" (Smith, 1997: 13). Por su parte, el nacionalismo es un fenómeno ideológico y puede separarse analíticamente de la nación. Es la aspiración a "formar parte de una unidad política y cultural reconocida, «la nación», y si es el caso, inventar una" (Smith, 1976: 271). Finalmente, Smith (1997: 13) plantea un "modelo estándar" de identidad nacional occidental que parte de una definición de nación como una conjunción de elementos tangibles: "un grupo humano designado por un gentilicio y que comparte un territorio histórico, recuerdos históricos y mitos colectivos, una cultura de masas pública, una economía unificada y derechos y deberes legales e iguales para todos sus miembros".

El problema con estas formas de argumentar la nación es que, si bien se presentan como tipos ideales, es muy difícil que todas las naciones, que históricamente han sido reconocidas como tales, encuadren en esos criterios. Por lo demás, es evidente que algunos rasgos, como la igualdad de derechos en la definición de Smith, sólo aplicarían en casos de democracias modernas occidentales y no precisamente a todo el legado occidental. Por ello, un segundo problema es que este tipo de definición, con tendencia eurocéntrica, se convierte en una norma necesaria o deseable en virtud de la cual juzgar la existencia de una nación, más que en una categoría "neutra" útil al análisis. Finalmente, estas concepciones "esencializan" en un conjunto de rasgos tangibles la identidad nacional con el fin de hacerla objetivamente verificable, pero no tienen en cuenta que estos rasgos -la lengua, el territorio compartido, por ejemplo- no necesariamente son esenciales a la existencia de una nación, sino que pueden cambiar con el tiempo o desaparecer sin que ello implique la desaparición de la conciencia nacional. Ello es así pese a que los movimientos nacionalistas siempre acudan a identificarse con rasgos tangibles para plantear sus demandas ${ }^{8}$.

\footnotetext{
${ }^{8}$ Un ejemplo arquetípico que permite constatar el carácter no esencial de ningún rasgo tangible para la existencia de nación es el irlandés. La identidad irlandesa sobrevivió a la muerte de su lengua, el gaélico. De allí que, como afirma Connor (1998: 46), "la identidad nacional puede sobrevivir a transformaciones sustanciales de la lengua, la religión, el estatus económico y cualquier otra manifestación tangible de su cultura. Lo que no obsta para que quienes están implicados en una disputa étnica no sólo tiendan a expresar su cultura nacional a través de símbolos tangibles; sino también a manifestar su aversión hacia la otra nación concretándola en atributos externos fácilmente identificables”. En el mismo sentido afirma Miller (1997: 39): “...es un error comenzar desde la posición de un observador exterior que intenta identificar a las naciones escrutando para ver qué personas tienen atributos comunes tales como la raza o la lengua. Es más, puede que encontremos gentes que comparten uno o más de estos atributos, y que sin embargo no constituyan una nación porque ellos mismos no piensan que formen una (los austriacos y los alemanes, por ejemplo). Por otra parte, si tomamos a aquellos pueblos que por el reconocimiento mutuo y las creencias compartidas constituyen naciones, no hay una única característica (como la raza o la religión) que tengan todos sus ciudadanos en común".
} 


\subsection{El argumento relativista-objetivista}

En contraste, las concepciones de Hobsbawm (2000) y Gellner (1988) enfatizan el carácter artificial e históricamente construido de la nación. Para estos autores, la nación es producto de la época moderna e industrial y está referida al Estado, aunque no se identifique con él. Gellner (1988: p. 20) concibe la nación como un tipo de cultura compartida que enmarca sistemas de ideas, signos, asociaciones y pautas de conducta y comunicación. Esta cultura sólo se desarrolla dentro de unas condiciones históricas propias de la "sociedad industrial", en las que el nacionalismo se explica por la necesidad objetiva de homogeneidad en una población caracterizada por la movilidad y por su carácter letrado y estandarizado.

Para ambos autores la nación sólo puede constatarse a posteriori por su vínculo con el Estado, por eso desplazan el análisis hacia el nacionalismo como la realidad presente. Gellner (1988: 80) sostiene que "el nacionalismo engendra naciones, no a la inversa", mientras Hobsbawm (2000: 18) afirma que "a efectos del análisis, el nacionalismo antecede a las naciones. Las naciones no construyen Estados y nacionalismos sino que ocurre al revés". En ambos casos, el nacionalismo es concebido como un movimiento que busca hacer coincidir la unidad política con la unidad nacional (Gellner, 1988: 13; Hobsbawm, 2000: 17); en otros términos, un movimiento que reclama autodeterminación por medio de la construcción de un Estado propio. En últimas, es el nacionalismo, que ha coronado con éxito su tentativa de construir un Estado propio, el que constituye la nación y en eso no hay nada esencial.

Aunque para ninguno de ellos los rasgos tangibles, como la lengua, la religión, la etnicidad, la cultura, el territorio o la pertenencia a una unidad política duradera, son esenciales para la existencia de una nación, no por ello les restan importancia en su análisis. Hobsbawm (2000: 55-88) los introduce con su concepto de lazos de identificación "protonacional", los cuales pueden convertirse en rasgos de identificación nacional, sin que entre uno y otro tipo de identificación medie un vínculo causal necesario. Incluso algunos de ellos -como la lengua o la religiónpueden ser inventados sobre la marcha del movimiento nacionalista o desde el Estado. En suma, el protonacionalismo no conduce al nacionalismo "lógica e inevitablemente" e incluso en momentos pueden entrar en contradicción; sin embargo, la existencia de lazos protonacionales facilita la tarea del nacionalismo (Hobsbawm, 2000: 86).

Por su parte, Gellner (1988: 91) introduce esos rasgos en su análisis de una manera similar mediante su concepto de rasgos de "entropifuguidad", el cual designa formas de clasificación de poblaciones que persisten en la sociedad industrial a pesar de la homogeneidad cultural, que empieza por la alfabetización en el sistema educativo sostenido por el Estado. Estos "rasgos entropífugos" tienden a concentrar individuos en un sector de la sociedad, pero la fortaleza o 
debilidad con que sean asumidos como rasgos de identificación depende de factores contingentes como las barreras de comunicación 0 el hecho de encontrarse irregularmente distribuidos en la sociedad, entre otros. Así pues, tampoco estos rasgos conducen necesariamente a movimientos nacionalistas, aunque estos si se valen de aquellos para identificarse y plantear sus demandas.

\subsection{El argumento relativista-subjetivista}

En esta misma perspectiva, que concibe la nación como una construcción histórica y artificial, también pueden ubicarse los argumentos de Renan (1987) y, mucho más recientemente, de Anderson (1997) y Connor (1998), aunque en sus definiciones enfatizan el carácter subjetivo -el imaginario, sentimiento o conciencia nacional-.

La conferencia Qué es una nación de Renan (1882) tiene como trasfondo la guerra franco-prusiana. El autor no se orienta tanto a justificar la autodeterminación nacional como a formular un argumento que impida que Alemania salga victoriosa en el diferendo sobre Alsacia y Lorena, apoyada en una concepción racial y espiritual de la nación. Por ello, más que en este tipo de elementos, pondrá el énfasis en la voluntad como factor definitorio de la nación. En ese sentido, empieza por señalar la novedad del fenómeno nacional y analiza históricamente la poca importancia que tienen elementos como raza, lengua, religión, comunidad de intereses, geografía y fronteras naturales, y necesidades militares, en la definición de las naciones ${ }^{9}$.

Más que en este tipo de elementos, su concepción de la nación pone el énfasis en elementos subjetivos, la voluntad de percibirse como nación:

"Una nación es un alma, un principio espiritual. Dos cosas que, a decir verdad, no son más que una, constituyen este alma, este principio espiritual. Una está en el pasado, la otra en el presente. La una es la posesión común de un rico legado de recuerdos; la otra es el consentimiento actual, el deseo de vivir juntos la voluntad de continuar haciendo valer la herencia que se ha percibido indivisa (...) Una nación es pues una gran solidaridad, constituida por el sentimiento de los sacrificios que se han hecho y los sacrificios que todavía se está dispuesto a hacer. Supone un pasado; se resume, no obstante, en el presente por un hecho tangible: el consentimiento, el deseo claramente expresado de continuar la vida en común" (Renan, 1987: 82-83).

\footnotetext{
${ }^{9}$ Por ejemplo, respecto a la raza afirma: "la consideración etnográfica no ha existido, pues, para nada en la constitución de las naciones modernas. Francia es celta, íbera y germánica. Alemania es germánica, celta y eslava. Italia es el país donde la etnografía está más embrollada: galos, etruscos, pelascos y griegos, sin mencionar otros muchos elementos, se cruzan allí en una mezcolanza indescifrable. Las islas británicas, en su conjunto, ofrecen una mezcla de sangre celta y germánica cuyas proporciones son difíciles de definir (...) La verdad es que no hay raza pura y hacer descansar la política sobre el análisis etnográfico es hacerla apoyarse sobre una quimera. Los países más nobles, Inglaterra, Francia, Italia, son aquellos en que la sangre está mezclada" (Renan, 1987: 72-73).
} 
La perspectiva de Anderson no desconoce el papel que desempeñan rasgos tangibles como elementos identificatorios -particularmente la lengua- en la formación del imaginario nacional, ni la referencia de la nación al Estado moderno y el papel que este puede desempeñar en la formación de dicho imaginario. No obstante, su concepción de la nación como "una comunidad política imaginada como inherentemente limitada y soberana" (Anderson, 1997: 23), enfatiza el carácter subjetivo. De acuerdo con Anderson (1997: 70), lo que hizo imaginables las comunidades fue la conjunción "semifortuita" entre las relaciones del sistema de producción capitalista, la tecnología de comunicaciones de la imprenta y la "fatalidad" de la diversidad lingüística.

Por su parte, Connor (1998: 45) sostiene que "el factor esencial para determinar la existencia de una nación no son las características tangibles de un grupo, sino la imagen que éste se forma de sí mismo". En otras palabras, advierte el autor, cuando se trata de la nación no importa tanto la "realidad" como lo que la gente cree que es "real". Esto le permite distinguir las categorías de nación y nacionalismo de la siguiente forma: "el vocablo nación se usa para referirse a un conjunto de personas que creen poseer una ascendencia común. Y nacionalismo se emplea para designar la identificación con la propia nación" (Connor, 1998: XIII). La nación es un mito fundado en el sentimiento de ascendencia compartida, mientras el nacionalismo es la lealtad a ese mito; por eso para el autor siempre se trata de "etnonacionalismo".

A diferencia de Anderson y los demás autores, Connor se esfuerza por liberar el concepto de nación de cualquier referencia a rasgos tangibles y por desmitificar lo que a su juicio es el error básico de los estudios sobre nación y nacionalismo: su referencia o asimilación al Estado. Eso no sólo le permite distinguir claramente entre nacionalismo -el sentimiento de lealtad hacia la nación- y patriotismo -el sentimiento de lealtad al Estado y al país (Connor, 1998: 185); sino admitir -a diferencia de los demás autores- que no todo nacionalismo tiene como objeto la construcción de un Estado propio ${ }^{10}$.

Estas perspectivas son más compatibles con el enfoque de este trabajo en tanto parte de una concepción de nación como construcción artificial e histórica y de una perspectiva no esencialista de la formación de las identidades colectivas. Sin

\footnotetext{
${ }^{10}$ Distinciones similares están presentes en los trabajos de Anthony Smith aunque, a diferencia de Connor, enfatizando los rasgos tangibles en la definición de la nación. Para Smith (1997: 13) "[Estado] se refiere exclusivamente a las instituciones públicas que son distintas e independientes de otras instituciones sociales, y que ejercen el monopolio de coerción y exacción dentro de un territorio determinado. La nación, por el contrario, representa un lazo cultural y político al unir en una única comunidad política a todos los que comparten una cultura y un suelo patrio históricos". Este argumento no tiene en cuenta que la cultura o algunos de sus rasgos también pueden ser considerados como tipos de "instituciones públicas", con lo cual se tornaría borrosa la distinción, o que rasgos como una "única comunidad política" o un "suelo patrio histórico" no son esenciales a la nación. Sin embargo, ello le permite arribar a una definición de nacionalismo similar a la de Connor, en la que el nacionalismo es ideología de la nación y no del Estado, y no todos los nacionalismos demandan inextricablemente un Estado propio (Smith, 1997: 68).
} 
embargo, ninguna de estas perspectivas enfatiza con suficiencia el proceso histórico de construcción de la nación, como un proceso necesariamente conflictivo. Si bien reconocen un proceso histórico que desemboca en la construcción de la nación, tienden a desconocer las relaciones de poder entre actores que conlleva todo proceso de definición del significado de una nación, cuando no soslayan definitivamente el conflicto para atribuirle la tarea de imaginar las comunidades a las élites (Chatterjee, 2000). De esa forma, se corre el riesgo de caer en concepciones que reducen el problema de la nación a su dimensión cultural, desconociendo que si hay algo necesario o esencial en la definición de una nación es lo político ${ }^{11}$.

Esta breve revisión de las formas como se ha argumentado la categoría de nación ha mostrado que existe una tensión epistemológica a la hora de identificar lo que permite definirla, principalmente por la necesidad de objetividad que debe tener por referencia esta categoría. Para Hobsbawm (2000: 13-16) las definiciones "objetivas" de la nación fracasan porque siempre hay excepciones de naciones que no cumplen con los rasgos definitorios y porque esos rasgos son ambiguos y cambiantes; también fracasan las definiciones "subjetivas" o "voluntaristas", para las cuales la existencia de una nación depende de que un grupo de personas se reclame como tal, por su carácter tautológico y porque sólo permiten conocer una nación a posteriori.

Entonces es necesario analizar la nación en medio de esta tensión cambiando de perspectiva. El problema no es si la nación es un fenómeno objetivo o subjetivo sino la forma como se produce el tipo de subjetividad que permite dotar la nación de significado. En otros términos, entre ambos extremos, rasgos objetivos y definiciones voluntaristas o subjetivistas de la nación, se encuentran las formas como los sujetos concretos dan significado a determinados rasgos objetivos que les permiten identificarse como nación. Este proceso, en el cual los sujetos dan significado a sus naciones, es necesariamente político y conflictivo y puede analizarse como la formación de una hegemonía. Esta perspectiva permite, a diferencia de las nociones ontologistas, introducir la nación en la dimensión histórica y concebirla como una invención en permanente transformación más que como un ente eterno e inmutable y, a diferencia de la perspectiva relativista, introducir como rasgo determinante en la definición de la nación lo político, las relaciones de poder entre sujetos concretos.

\section{La nación: significante vacío u objeto imposible}

Desde este punto de vista, la construcción de la nación siempre es objeto de lucha o enfrentamiento entre diferentes proyectos de nación, entre las diferentes concepciones de lo que debe ser la nación, entre diferentes maneras de imaginar

\footnotetext{
${ }^{11}$ Ello no quiere decir que la "cultura" no esté perneada por lo político y viceversa, antes bien, lo que quiere decir es que la construcción de "artefactos culturales" como la nación no pueden entenderse al margen de lo político.
} 
la comunidad nacional que abanderan sujetos históricos concretos. No se trata de verificar si las naciones se aproximan o no a un tipo ideal de nación, sino de analizar la manera como la nación, o lo que esta deber ser, es concebida por los sujetos concretos y la forma en que sus proyectos de nación entran en pugnacidad por definir las naciones dando significado a elementos objetivos de su realidad. Por ello es necesario introducir lo político en el análisis.

Hay varias formas de introducir la dimensión propiamente política en el análisis del fenómeno nacional. Una de ellas es la que propone Schnapper (2001) cuando plantea la necesidad de volver a ver en el vínculo social un hecho esencialmente político y, por tanto, nacional. Otra es la que se puede encontrar en ciertas perspectivas marxistas y en el debate de la segunda internacional socialista de principios del siglo $\mathrm{XX}$, que hacían énfasis en las relaciones conflictivas entre clases como factor definitorio de la nación.

La preocupación central de Schnapper (2001: 13) es rescatar una perspectiva de la nación que se remonta a la Revolución Francesa y que la concebía como

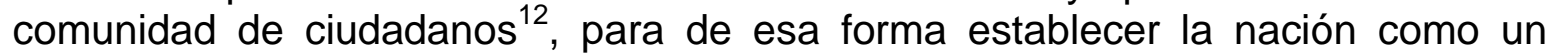
vínculo específicamente político. Al respecto afirma: "para formar una nación no es suficiente ninguna de las características de las poblaciones. Es la organización política la que crea y la que da significado a las características Ilamadas objetivas" (Schnapper, 2001: 52). De acuerdo con Schnapper, la nación es un producto de la modernidad, surgió entre los siglos XVI y XIX en Europa occidental y Norteamérica y de ahí se difundió al resto del mundo. Su definición de la nación es esencialmente política:

"La especificidad de la nación moderna consiste en integrar a toda la población en una comunidad de ciudadanos y en legitimar, mediante esta comunidad, la acción del Estado, que constituye su instrumento. Implica pues, el principio del sufragio universal (participación de todos los ciudadanos para elegir a los gobernantes y juzgar las formas de ejercicio del poder) y servicio militar (participación de todos los ciudadanos en la acción exterior)" (Schnapper, 2001: 51) ${ }^{13}$.

Esta concepción distingue la nación de la etnia porque esta no tiene una organización política autónoma, es decir, la especificidad del vínculo político, sino un vínculo por la creencia en una ascendencia compartida (Schnapper, 2001: 31). Empero, sus problemas empiezan cuando trata de distinguir la nación del Estado,

\footnotetext{
12 La socióloga francesa parte de un diagnóstico según el cual “... la evolución interna de las democracias, en las que la vida colectiva parece centrarse en la producción de riquezas y en su distribución, tiende a minar la idea política originaria de las naciones, hasta el punto de que a las democracias les resulte imposible exigir a sus ciudadanos defenderlas si con ello han de pagar con la vida" (Schnapper, 2001: 13).

${ }_{13}$ "Al igual que toda comunidad política, la nación se define por la soberanía que tiene como efecto, en el interior, integrar a las poblaciones que incluye, y en el exterior, afirmarse en cuanto sujeto histórico en un orden mundial basado en la existencia y las relaciones entre naciones-unidades políticas. Pero su especificidad consiste en que integra a las poblaciones en una comunidad de ciudadanos cuya existencia legitima la acción interior y exterior del Estado" (Schnapper, 2001: 2829).
} 
o de las instituciones que le dan especificidad a las "naciones-unidades políticas" y garantizan los supuestos básicos de la "comunidad de ciudadanos", de tal forma que, aún cuando se advierte lo contrario, ambos aparecen como indistintos ${ }^{14}$. Además, las capacidades heurísticas y analíticas de la categoría de nación, tal como se plantea, se reducen en la medida que liga necesariamente la idea de nación con la idea de democracia, con la soberanía del pueblo, o de la "comunidad de ciudadanos", con lo cual limita el potencial de análisis a unos pocos casos de democracias modernas y occidentales, y tiende a caer en cierto eurocentrismo ${ }^{15}$. Finalmente, su concepción de lo político se reduce a lo político-estatal, la dimensión estructural, y a una determinada concepción del Estado y el régimen político democrático, descuidando las relaciones de poder entre sujetos concretos y su papel en la definición de la nación.

Muy distinta es la concepción de lo político que se puede encontrar en el debate sobre la cuestión nacional en el interior de la socialdemocracia, sistemáticamente soslayado en la literatura contemporánea, y más en general, en enfoques marxistas ${ }^{16}$. Estas perspectivas resaltan el carácter político y, por tanto, conflictivo del proceso de construcción de la nación, y de toda identidad colectiva, y se hallan presentes en trabajos que concebían la nación como el resultado de una compleja relación de fuerzas entre clases sociales. Como afirmara Torres Rivas en su clásico estudio (1981: 105-106):

\footnotetext{
14 "El Estado, en cuanto conjunto de instituciones y medios de control y de coerción, que tienen por objeto crear y mantener la cohesión interna de las unidades políticas y permitirles ejercer su acción en el exterior, es a la vez la expresión y el instrumento de toda unidad política moderna. Es el Estado el que diferencia a todas las naciones-unidades políticas de las demás formas de colectividad o etnias. En el caso de la nación democrática, es, como dice Hegel, el soporte nacional de la nación que, sin él, no tendría una existencia verdadera y la expresión objetiva de la identidad colectiva, que se ha vuelto política. Pero este vínculo necesario no debe llevar sin embargo a su asimilación. Por el contrario, es la existencia de una comunidad de ciudadanos, distinta del Estado, lo que convierte a la nación democrática en algo específico entre las unidades políticas" (Schnapper, 2001: 36).

${ }^{15}$ En el fondo la autora pretende rescatar una concepción liberal de la nación, amenazada por la irrupción de etnonacionalismos. De esa forma se pueden entender afirmaciones como ésta: "...escribir que el ciudadano «debe» respetar la ley no es dar un consejo o una orden en nombre de una moral cívica y política -como se hacía en los libros de instrucción cívica de nuestros abuelos en la época de la nación triunfante-, sino mostrar que esta conducta se inscribe en la lógica misma del funcionamiento de la nación democrática, develar el sentido objetivo y formular los valores que la fundan no significa adherirse a la nación o defenderla contra sus detractores políticos o intelectuales" (Schnapper, 2001: 24).

${ }^{16}$ Como es bien sabido, Marx y Engels no se ocuparon sistemáticamente del problema. Una compilación de sus intervenciones en Marx y Engels (1980). Haupt y Weill (1980: 11-12) sostienen que el problema nacional es marginal frente a los demás problemas por ellos estudiados. Pero señalan como puntos más o menos aceptados en las intervenciones de estos autores sobre el problema nacional: primero, la nación es una condición objetiva, producto del desarrollo histórico y no una elección subjetiva; segundo, la nación moderna es una categoría histórica ligada al modo de producción capitalista y al Estado centralizado; tercero, es producto e instrumento de la burguesía en ascenso; cuarto, es un espacio de lucha de clases y sirve a los intereses de la clase que se impone. También resaltaron las peculiaridades nacionales abandonando el determinismo histórico y por tanto el desarrollo de una teoría de la nación universalmente válida.
} 
"En sus formas más desarrolladas la comunidad cultural puede ser contenida en una forma nacional y es por lo general la valorización de aquello que constituye a juicio de la clase dominante un conjunto de valores fundantes... La llamada cultura nacional es siempre cultura de clase [...] El paradigma del estado nacional burgués es aquel en que la integración política y cultural de las clases, pulverizadas en la falsa igualdad de la ciudadanía universal, se encuentra soldada en el cemento ideológico de una poderosa identificación nacional supraclase. En última instancia, la integración cultural es un acto de hegemonía política, y en ese ejercicio de dominación de clase el nacionalismo es una ideología al servicio de la burguesía".

La emergencia de movimientos nacionalistas a fines del siglo XIX planteó un gran problema al internacionalismo proletario, el cual atizó la discusión sobre el problema de la "autodeterminación de las naciones". Entre las intervenciones más connotadas sobre el problema se destacaron en su momento la de Rosa Luxemburg (1908-1909) y la respuesta de Lenin ${ }^{17}$. Siguiendo a Marx y Engels, que no se fundamentaban en fórmulas abstractas sobre el problema sino que examinaban los casos concretos, Luxemburg criticó violentamente el postulado adoptado en el Congreso Internacional de Londres (1896), el "derecho a la autodeterminación de la naciones".

En su lectura, en primer lugar, esta consigna no ofrecía información para una política práctica por parte de la socialdemocracia ${ }^{18}$. Segundo, la posibilidad real de autodeterminación de todas las nacionalidades era una utopía debido a las tendencias del desarrollo histórico del capitalismo y el accionar de los "poderes mundiales" y el "imperialismo capitalista"19. Finalmente, el concepto de nación, tal como se planteaba, encubría el conflicto de clases:

"La fórmula del "derecho de las naciones a la autodeterminación" es inadecuada para justificar la posición de los socialistas ante la cuestión nacional, no sólo porque no toma en cuenta ni la gran variedad de condiciones históricas (lugar y tiempo) que existe en cada caso concreto ni el curso general de las condiciones globales, sino porque ignora totalmente la teoría fundamental del socialismo moderno: la teoría de las clases sociales. Cuando hablamos del "derecho de las naciones a la autodeterminación" estamos utilizando el concepto de "nación" como una entidad social y política homogénea. Pero en realidad un concepto como el de "nación" constituye una de esas categorías de la ideología burguesa que, como la "libertad del ciudadano", la "igualdad ante la ley", etc., la teoría marxista ha

\footnotetext{
${ }^{17}$ Quien reivindicó primero la autodeterminación nacional fue Kautsky (1978), quien estableció las líneas generales del debate que suscitó la inclusión del derecho a la autodeterminación en el Congreso Internacional de Londres (1896).

18 "... la fórmula del "derecho de las naciones a la autodeterminación" no es en esencia una consigna ni una guía política o programática para abordar la cuestión de las nacionalidades sino tan sólo un medio para eludir la cuestión" (Luxemburg, 1998: 21).

19 "...el desarrollo histórico, especialmente el moderno desarrollo del capitalismo, no tiende a devolver a cada nacionalidad una existencia independiente, sino que se mueve en dirección opuesta" (Luxemburg, 1998: 37).
} 
sometido a una revisión radical, demostrando que tras esa cortina de humo se esconde en todos los casos un contenido histórico bien definido. En una sociedad de clases, la "nación" como entidad sociopolítica homogénea no existe. Lo que si existe en cada nación son clases con intereses y "derechos" antagónicos" (Luxemburg, 1998: 48).

"En una sociedad así constituida no cabe hablar de una voluntad colectiva y uniforme, de la autodeterminación de la "nación". Cuando en la historia de las sociedades modernas encontramos movimientos "nacionales" y luchas a favor de "intereses nacionales", suelen ser movimientos de clase de los estratos dirigentes de la burguesía, que en un momento dado pueden representar los intereses de otros estratos sólo en la medida en que bajo la forma de "intereses nacionales" defienden formas progresivas del desarrollo histórico y en la medida en que la clase trabajadora aún no se ha diferenciado como tal de la masa de la "nación" (liderada por la burguesía) lo suficiente como para formar una clase política independiente y consciente" (Luxemburg, 1998: 49-50).

Lenin criticó con la misma furia estos postulados para defender la proclamación del derecho de las naciones a la autodeterminación. Principalmente, en su lectura, Luxemburg habría truncado el entendimiento de la "autodeterminación", que para él se trataba de la formación de estados independientes por "naciones oprimidas"20. "el problema de la autodeterminación de las naciones en la sociedad burguesa, de su independencia estatal, lo sustituye Rosa Luxemburgo por el de la autonomía e independencia económica” (Lenin, 1969: 14). Ello explicaba por qué Luxemburg se mostró reacia a la proclamación del derecho a la autodeterminación de las naciones, en la medida en que consideró que las condiciones del desarrollo capitalista lo impedían por la vía del imperialismo. De ahí también que llegase a plantear que una autodeterminación real de las naciones sólo sería posible después de construir el socialismo internacional.

Sin embargo, en el fondo ambos autores compartían un entendimiento similar de la nación. Por una parte, para ambos se trató de un fenómeno propio del desarrollo capitalista y del ascenso de la burguesía ${ }^{21}$. En segundo lugar, ambos señalaron, siguiendo a Marx y Engels, que el problema nacional sólo podría comprenderse en un contexto histórico concreto, las particularidades de cada país

\footnotetext{
20 "...si queremos entender lo que significa la autodeterminación de las naciones, sin jugar a definiciones jurídicas ni "inventar" definiciones abstractas, sino examinando las condiciones histórico-económicas de los movimientos nacionales llegaremos inevitablemente a la conclusión siguiente: por autodeterminación de las naciones se entiende su separación estatal de las colectividades nacionales extrañas, se entiende la formación de un Estado nacional independiente" (Lenin, 1969: 11).

21 "En todo el mundo, la época del triunfo definitivo del capitalismo sobre el feudalismo estuvo ligada a movimientos nacionales. La base económica de estos movimientos estaba en que, para la victoria completa de la producción mercantil, es necesario que la burguesía conquiste el mercado interior, es necesario que territorios con población de un solo idioma adquieran cohesión estatal, quedando eliminados cuantos obstáculos se opongan al desarrollo de ese idioma y a su consolidación en la literatura" (Lenin, 1969: 10-11).
} 
en un marco histórico más amplio (Lenin, 1969: 17) ${ }^{22}$. Finalmente, y lo más importante, para ambos la nación es un resultado de las relaciones de poder entre clases.

Para Luxemburg, justamente la tarea de la socialdemocracia era formar una "voluntad nacional" y constituirse en mayoría:

"La socialdemocracia, por su propia naturaleza, es una partido que representa los intereses de la inmensa mayoría de la nación. Pero también es, en el seno de la sociedad burguesa y en la medida en que se trata de expresar la voluntad consiente de la nación, el partido de una minoría que busca convertirse en mayoría... la misión histórica de la socialdemocracia se basa ante todo en revolucionar y formar la voluntad de la "nación", es decir, de su mayoría trabajadora" (Luxemburg, 1998: 56).

Para Lenin, si bien el proletariado debía estar en contra de todos los privilegios, aún en contra de los de las burguesías de naciones oprimidas, también debía apoyar estratégicamente sus luchas, mientras estas se alinearan en contra de las burguesías de naciones opresoras o imperialistas. De esa forma, contemplaba la posibilidad de alianzas entre clases para hacer frente al problema nacional:

"Si la burguesía de una nación oprimida lucha contra la opresora nosotros estamos siempre, en todos los casos y con más decisión que nadie, a favor, ya que somos los enemigos más audaces y consecuentes de la opresión. Pero si la burguesía de la nación oprimida está por su nacionalismo burgués, nosotros estamos en contra. Lucha contra los privilegios y violencias de la nación opresora y ninguna tolerancia con respecto a la tendencia de la nación oprimida hacia los privilegios (Lenin, 1969: 34-35).

Esta perspectiva devuelve al concepto de nación la historicidad ubicándolo en el terreno de las luchas de poder concretas y contiene los elementos necesarios para analizar la nación como producto de una lucha hegemónica. Sin embargo, aun es necesario resaltar que la integración nacional es un proceso contingente, resultado de las relaciones de poder entre sujetos sociales y políticos, y no un resultado necesario del desarrollo de las fuerzas productivas y la unificación por la vía del mercado, tal como lo suponen ciertas lecturas del marxismo (Torres, 1981: 103). En otras palabras, la nación no es sólo un epifenómeno "superestructural" determinado por la economía; tiene "vida propia". También es necesario enfatizar que los actores protagónicos del proceso no tienen por qué ser necesariamente las clases sociales, ni ningún otro sujeto constituido con anterioridad a la lucha hegemónica. Resaltar el carácter conflictivo del proceso de construcción de la nación es posible si se complementa la perspectiva que concibe la nación como una construcción artificial e histórica, con las premisas para el estudio de las identidades colectivas desarrolladas por Laclau y Mouffe (1987).

\footnotetext{
22 "A partir de las premisas generales del materialismo histórico, la posición de los socialistas ante los problemas nacionales depende sobre todo de las circunstancias concretas de cada caso, que difieren notablemente de un país a otro y cambian también con el paso del tiempo en cada país (Luxemburg, 1998: 23).
} 
A grandes rasgos, en la perspectiva gramsciana el concepto de hegemonía designaba la articulación de los intereses de clases distintas con el fin de formar una "voluntad colectiva nacional popular". Ello suponía no sólo una transformación política "institucional" sino también la definición de la "realidad", del "sentido común" y la formación de "nuevos sujetos" (Mouffe, 1985: 137). Siguiendo a Laclau y Mouffe (1987: 105-166), la hegemonía no es una articulación necesariamente entre clases, pues los sujetos articuladores constituyen su identidad en medio de la lucha. En otros términos, a diferencia de esa perspectiva, en su teoría de la hegemonía los sujetos en lucha no necesariamente son las clases sociales, dado que la identidad no es producto de la posición de los sujetos en la estructura social, como la identidad del sujeto clase en el marxismo, ni es una esencia, sino que se define en función de relaciones. Se parte del supuesto de que toda identidad es relacional (Laclau y Mouffe, 1987: 120) ${ }^{23}$.

Los sujetos construyen su identidad como resultado de la lucha hegemónica, no son anteriores a ella. Es esa lucha lo que permite definir los contornos de su identidad y su diferencia con el otro. Los sujetos se constituyen estableciendo relaciones de articulación y antagonismo. Los sujetos se definen como tales, construyen su identidad, articulándose con otros que de alguna forma puedan construir un proyecto común. Lo que permite la articulación es que esos diversos puedan constituirse en equivalentes, pese a sus diferencias, frente a un adversario común, un "otro" antagónico al que resulta imposible articular a la lucha (Laclau y Mouffe, 1987: 145) ${ }^{24}$.

\footnotetext{
${ }^{23}$ Laclau y Mouffe parten de un cuestionamiento a los enfoques esencialistas que conciben las identidades colectivas como constructos determinados por la posición estructural de los sujetos (el concepto de clase en ciertas perspectivas marxistas), o como identidades plenamente constituidas (totalidades dadas) previas a toda relación social. En su perspectiva, toda identidad tiene un carácter relacional, no hay nada esencial que determine su formación, lo único necesario es el carácter relacional de las identidades (Laclau y Mouffe, 1987: 120). Las identidades no son previas a la relación, sino una de sus consecuencias. Ello implica que tienen siempre un "carácter incompleto, abierto y políticamente negociable" (Laclau y Mouffe, 1987: 118). De allí que en vez de sujetos plenamente constituidos, como la clase, prefieran hablar de "posiciones de sujeto". El carácter relacional de las identidades "no es sino otra forma de decir que no hay identidad que logre constituirse plenamente" (Laclau y Mouffe, 1987: 127), o que toda identidad se caracteriza por una "falta de sutura última".

${ }^{24}$ El carácter precario de la identidad, no implica que no se puedan reconocer de alguna manera sus límites, aunque implica que esos límites serán siempre parciales e inestables. De acuerdo con los autores, las identidades se forman a partir de articulaciones, concebidas como prácticas que establecen relaciones entre elementos, como resultado de las cuales la identidad de los mismos resulta modificada (Laclau y Mouffe, 1987: 119). De allí que la fijación parcial del significado de la identidad dependa de la forma de articulación hegemónica y de la "cadena de equivalencias" en que se inscriban los elementos articulados. En esta lógica, lo que hace posible distinguir los límites de las identidades es el antagonismo. Una relación que establece los límites siempre parciales a los sistemas de diferencias y equivalencias que constituyen las identidades, en la medida en que "la presencia del "Otro» me impide ser totalmente yo mismo. La relación no surge de identidades plenas, sino de la imposibilidad de constitución de las mismas" (Laclau y Mouffe, 1987: 145).
} 
Finalmente, la hegemonía siempre supone relaciones de articulación, posibilidades de alianzas entre distintos sujetos y de formación de un proyecto político común, pues ello es lo que garantiza su aceptación, el "consentimiento" de los subordinados. En este sentido, la hegemonía se distingue de otros tipos de relaciones políticas como la subordinación o la dominación, que presuponen que no hay posibilidad de articulación entre los sujetos allí inmersos, entre dominantes y dominados (Laclau y Mouffe, 1987: 159). El carácter fluido e inestable de las identidades implica la imposibilidad de constituir una identidad que excluya totalmente y para siempre la posibilidad de articular elementos considerados como del "Otro". A diferencia de las otras formas de relación política, la hegemonía es una fijación parcial y contingente del sentido de lo social, dado que "ninguna lógica hegemónica puede dar cuenta de la totalidad de lo social y constituir su centro, ya que en tal caso se habría producido una nueva sutura y el concepto mismo de hegemonía se habría autoeliminado" (Laclau y Mouffe, 1987: 163). Este concepto permite pensar el problema sin omitir en el análisis las relaciones de subordinación que caracterizan la lucha por dotar de significado las naciones.

Esta perspectiva también permite recuperar en un sentido positivo la ambivalencia que ha caracterizado el concepto de nación (Delanoi, 1993). La ambivalencia, el carácter precario de la categoría de nación, no puede obviarse y, antes que denigrar de ella en nombre de la objetividad y la coherencia lógica, hay que hacerla objeto del análisis. En esa medida, la nación se puede concebir como un "significante vacío", cuyo significado depende de las relaciones de poder entre proyectos de nación encarnados por sujetos concretos. De acuerdo con Laclau (1996: 36-46) todo proyecto político requiere cierta vaguedad o ambigüedad pues ello es lo que le permite articular y representar demandas e intereses diversos para tornarse hegemónico. Ello hace de la nación un "objeto imposible", más que un agregado de elementos objetivos o una esencia trascendente, un significante cuyo significado está permanentemente en disputa.

La lógica hegemónica implica que cualquiera que sea el significado o el contenido de la nación, dado por sujetos concretos en disputa, tendrá que articular de alguna manera elementos de los sectores subordinados, pues como afirma Žižek (1998: 140) las ideas dominantes, en este caso la nación, no son las ideas de quienes dominan, siempre articulan ideas, aspiraciones o sentimientos de los oprimidos. Esta perspectiva es compatible con la definición de nación de Anderson (1997: 23), a condición de reconocer, por una parte, que si bien la nación es una "comunidad imaginada", no todos los actores y sectores sociales tienen la posibilidad de imaginarla en la misma proporción, o no todos los proyectos de nación imaginados logran cristalizar como tal. Antes bien, aquí es pertinente preguntarse “¿De quién es la comunidad imaginada?” (Chatterjee, 2000).

Por otra parte, contrario a lo que piensa Anderson (1997: 25), para quien las comunidades nacionales siempre se imaginan como comunidades de iguales pese a las desigualdades evidentes, es necesario señalar que esto no siempre es así. Si bien esa suposición es verificable en los casos occidentales donde se imaginaron comunidades de ciudadanos libres e iguales, tal suposición no es 
generalizable a casos poscoloniales en los que en ciertos momentos la nación pudo imaginarse como una comunidad de desiguales, o por lo menos se produjeron luchas entre quienes imaginaban la nación de una u otra de estas formas.

La lucha por la definición de la nación tiene lugar entre proyectos de nación diferentes y/o antagónicos. Si bien la nación se inscribe en el plano de lo simbólico, esta lucha no se agota en la esfera cultural, se extiende a todos los niveles, especialmente los referidos al reconocimiento de derechos y el ejercicio del poder. Un proyecto de nación se entiende como la forma particular en que un actor social o político, un sujeto concreto, concibe que debe ser la nación; en otras palabras, la forma particular como imagina la comunidad nacional ${ }^{25}$.

La nación estará dotada de significado o será definida por el proyecto de nación hegemónico, es decir, el que logre estabilizar las relaciones sociales en su favor, construir una nueva subjetividad, un sentido común. Sin embargo, la lógica hegemónica, tal como ha sido planteada, implica que siempre esa definición de la nación será parcial, incompleta y negociable, y que necesariamente el proyecto hegemónico de nación articulará elementos del o los proyectos de nación subordinados.

Además, implica que el contenido o significado de la nación no está dado de una vez y para siempre, sino que es cambiante con el tiempo y su dinámica está determinada por las relaciones de poder entre proyectos de nación antagónicos. Estas relaciones definen las capacidades articulatorias de los proyectos de nación así como los límites o antagonismos que definen su identidad. De ahí que los proyectos de nación se transformen con el tiempo en virtud de las articulaciones que los constituyen y sus relaciones con los otros proyectos. Esto permite observar la manera en que el significado de las naciones se transforma al calor de la "política cultural", es decir, de las estrategias de los sujetos por desestabilizar su significado hegemónico ${ }^{26}$.

${ }^{25}$ Es conveniente distinguir en el análisis el concepto normativo de nación, aquí denominado proyecto de nación, que aglutina a uno u otro sector, del concepto analítico o explicativo, sin que ello implique una imposición de este sobre aquél. Knight (2000: 124) establece esta distinción entre la "identidad nacional [a] como un concepto supuestamente objetivo y científico, capaz de explicar los procesos históricos, y [b] como norma o concepto manejado por los propios actores históricos. La categoría [b] tiene importancia (en términos «fenomenológicos») independientemente de la validez de [a]. La categoría [a] ubica la «identidad nacional» al lado de otras categorías supuestamente objetivas, científicas y explicativas... La categoría [b] en contraste puede tener un alto contenido normativo e ideal: es decir, los actores históricos proponen y apoyan conceptos rivales de la identidad nacional". Si bien esta distinción es útil analíticamente debe manejarse con flexibilidad pues siempre se corre el riesgo de establecer la categoría de análisis como un deber ser o un telos necesario y deseable de nación, o bien establecer uno de los conceptos de identidad nacional rivales como el verdadero. La categoría analítica debe usarse como un patrón de contraste más que como una norma necesaria y deseable.

26 "Interpretamos política cultural como el proceso que se desata cuando entran en conflicto conjuntos de actores sociales que a la vez que encarnan diferentes significados y prácticas culturales, han sido moldeados por ellos... Es decir, cuando los movimientos despliegan conceptos alternativos de mujer, naturaleza, raza, economía, democracia o ciudadanía, los cuales 


\section{Conclusión}

Las formas de argumentación en la definición de la categoría de nación han fracasado en su intento de comprender el fenómeno al no tener en cuenta su historicidad y verse envueltos en una tensión epistemológica por la necesidad de objetividad que, se supone, esta categoría debe tener por referencia. Las argumentaciones ontologistas fracasan en el intento de comprender el fenómeno nacional porque conciben la nación como una esencia o "ser" trascendente a las dinámicas históricas de los sujetos, en su variante espiritualista, o como un conjunto de rasgos tangibles y un deber ser necesario y deseable, en su variable objetivista, "esencializando" en un conjunto de rasgos tangibles la existencia de la nación; las argumentaciones relativistas porque aunque hacen mella en el carácter histórico y construido de la nación, soslayan las relaciones de poder entre sujetos concretos.

En contraste, analizar la nación como un significante vacío o un objeto imposible resultado de una lucha hegemónica permite, frente a las argumentaciones ontologistas, introducir la nación en la dimensión histórica y concebirla como una invención en permanente transformación más que como un ente eterno e inmutable y, a diferencia de las relativistas, introducir como rasgo determinante en la definición de la nación lo político, las relaciones de poder entre sujetos concretos.

La nación no es una suma de elementos tangibles que se pueda descomponer en sus partes, sino una construcción social y política en la que sujetos concretos dan significado a rasgos o elementos objetivos para identificarse como tal. Es el resultado de una lucha entre proyectos de nación encarnados por sujetos concretos en pugna por dotarla de significado y constituirse en proyectos de nación hegemónicos. En este sentido, no es una invención definitiva sino un proceso de construcción permanente, que se transforma al calor de las luchas de los actores que buscan definirla. El significado de la nación nunca está plenamente logrado, es objeto de disputa entre las diferentes formas de imaginarla, entre proyectos antagónicos de nación. El estudio de la nación más que precisar su significado o el imaginario nacional en si mismo, debe orientarse hacia el estudio de la forma como se construye este significado o este imaginario, como se produce un tipo de subjetividad, resultado de la lucha entre los distintos significados e imaginarios posibles.

Esta es una lucha hegemónica, no una contraposición entre dominantes y dominados. Ello implica que ninguno de los actores en conflicto en el proceso de construcción de la nación está en capacidad de fijar por si sólo su significado. En este proceso no se producen exclusiones definitivas, aunque alguna de las formas

desestabilizan significados culturales dominantes, ponen en marcha una política cultural" (Escobar et al, 2001: 25-26). 
de imaginar la nación consiga la hegemonía. Los proyectos hegemónicos de nación son aquellos que consiguen articular otros sujetos y otros proyectos para conseguir su aceptación, su consentimiento, y dotar de significado la nación, que siempre se presenta como elemento unificador.

\section{Bibliografía}

Anderson, Benedict, 1997. Comunidades imaginadas. Reflexiones sobre el origen y la difusión del nacionalismo. México: FCE.

Bauer, Otto, 1979. La cuestión de las nacionalidades y la socialdemocracia. México: Siglo XXI.

Bolívar, Ingrid Johanna, 2001. Cuadernos de nación. Nación y sociedad contemporánea. Bogotá: Ministerio de Cultura.

Chatterjee, Partha, 2000. "Whose imagined community". En: Balakrishnan, Gopal (Ed.), Mapping the nation. London: Verso.

Connor, Walker, 1998. Etnonacionalismo. Madrid: Trama.

Delanoi, Gil, 1993. "La teoría de la nación y sus ambivalencias". En: Delannoi, Gil y Taguieff, Pierre-André (Comps.). Teorías del nacionalismo. Barcelona: Paidós, pp. 9-17.

Escobar, Arturo; Álvarez, Sonia y Dagnino, Evelina, 2001. "Introducción. Lo cultural y lo político en los movimientos sociales latinoamericanos". En: Escobar Arturo; Alvarez, Sonia y Dagnino, Evelina (Eds.). Política cultural y cultura política. Una mirada sobre los movimientos sociales latinoamericanos. Bogotá: TaurusICANH.

Fichte, J.G., 1968. Discursos a la nación alemana. Madrid: Taurus.

Gellner, Ernest, 1988. Naciones y nacionalismo. Madrid: Alianza.

Haupt, Georges y Weill, Claude, 1980. "Marx y Engels frente al problema de las naciones". En: Marx K. y Engels F. 1980, La cuestión nacional y la formación de los estados. México: Siglo XXI (Cuadernos de pasado y presente No 69), pp. 7-50. Hobsbawm, Eric, 2000. Naciones y nacionalismo desde 1780. Barcelona: Crítica. Jaffrelot, Christophe, 1993. "Los modelos explicativos del origen de las naciones y del nacionalismo. Revisión crítica”. En: Delannoi, Gil y Taguieff, Pierre-André (Comps.). Teorías del nacionalismo. Barcelona: Paidós, pp. 203-254.

Kautsky, Karl, 1978. La nacionalidad moderna. México: Siglo XXI (Cuadernos de pasado y presente No 73).

Knight, Alan, 2000. "La identidad nacional: ¿mito, rasgo o molde?” En: Sánchez, Gonzalo y Wills, Maria Emma (Comps.). Museo, memoria y nación. Misión de los museos nacionales para los ciudadanos del futuro. Bogotá: ICANH-IEPRIMinisterio de Cultura, pp. 119-155.

Laclau, Ernesto y Mouffe, Chantal, 1987. Hegemonía y estrategia socialista. Hacia una radicalización de la democracia. Madrid: Siglo XXI.

Laclau, Ernesto, 1993. Nuevas reflexiones sobre la revolución de nuestro tiempo. Buenos Aires: Nueva Visión. 
Laclau, Ernesto, 1996. "Why do Empty Signifiers Matter to Politics?". En Emancipations, London: Verso, pp. 36-46.

Lenin V.I., 1969. El derecho de las naciones a la autodeterminación. México: Grijalbo.

Luxembug Rosa, 1998. La cuestión nacional. Barcelona: El Viejo Topo.

Marx, K. y Engels, F., 1980. La cuestión nacional y la formación de los estados. México: Siglo XXI (Cuadernos de pasado y presente No 69).

Miller, David, 1997. Sobre la nacionalidad. Autodeterminación y pluralismo cultural. Buenos Aires: Paidós.

Mouffe, Chantal, 1985. "Hegemonía, política e ideología”, En: Labastida Martín del Campo Julio (Coord.). Hegemonía y alternativas políticas en América Latina. (Seminario de Morelia). México: Siglo XXI, 1985, pp. 125-145.

Renan, Ernest, 1987. ¿Qué es una nación? Cartas a Strauss. Madrid: Alianza.

Renaut, Alain, 1993. "Lógicas de la nación”. En: Delannoi Gil y Taguieff PierreAndré (Comps.), Teorías del nacionalismo. Barcelona, Paidós, pp. 37-62.

Santamaría, Antonio, 2005. "El estado de la cuestión: nacionalismo, identidad y etnicidad. Nuevos enfoques, nuevas teorías". En El Viejo Topo No 203-204, febrero-marzo.

Schnapper, Dominique, 2001. La comunidad de ciudadanos. Acerca de la idea moderna de nación, Madrid: Alianza.

Smith, Anthony D., 1976. Las teorías del nacionalismo. Barcelona: Península.

Smith, Anthony D., 1997. La identidad nacional. Madrid: Trama.

Stalin, José, 1972. Acerca de la cuestión nacional. Bogotá: Oveja Negra.

Torres Rivas, Edelberto, 1981. "La nación: problemas teóricos e históricos". En: Lechner Norbert (ed.). Estado y política en América Latina. México: Siglo XXI, 1ra Ed., pp. 87-132.

Žižek, Slavoj, 1998. "Multiculturalismo o la lógica cultural del capitalismo multinacional". En: Jameson, Fredric y Žižek, Slavoj. Estudios culturales. Reflexiones sobre el multiculturalismo. Buenos Aires: Paidós. 